\title{
BMJ Open Telehealth and patient satisfaction: a systematic review and narrative analysis
}

Clemens Scott Kruse, Nicole Krowski, Blanca Rodriguez, Lan Tran, Jackeline Vela, Matthew Brooks

To cite: Kruse CS, Krowski N, Rodriguez B, et al. Telehealth and patient satisfaction: a systematic review and narrative analysis. BMJ Open 2017;7:e016242. doi:10.1136/ bmjopen-2017-016242

- Prepublication history and additional material for this paper are available online. To view these files please visit the journal online (http://dx.doi. org/10.1136/bmjopen-2017016242).

Received 2 February 2017 Revised 23 June 2017 Accepted 23 June 2017
CrossMark

Texas State University, San Marcos, Texas, USA

Correspondence to Dr Clemens Scott Kruse; scottkruse@txstate.edu, scottkruse@sbcglobal.net

\section{ABSTRACT}

Background The use of telehealth steadily increases as it has become a viable modality to patient care. Early adopters attempt to use telehealth to deliver high-quality care. Patient satisfaction is a key indicator of how well the telemedicine modality met patient expectations.

Objective The objective of this systematic review and narrative analysis is to explore the association of telehealth and patient satisfaction in regards to effectiveness and efficiency.

Methods Boolean expressions between keywords created a complex search string. Variations of this string were used in Cumulative Index of Nursing and Allied Health Literature and MEDLINE.

Results 2193 articles were filtered and assessed for suitability $(n=44)$. Factors relating to effectiveness and efficiency were identified using consensus. The factors listed most often were improved outcomes (20\%), preferred modality (10\%), ease of use $(9 \%)$, low cost $8 \%)$, improved communication (8\%) and decreased travel time $(7 \%)$, which in total accounted for $61 \%$ of occurrences. Conclusion This review identified a variety of factors of association between telehealth and patient satisfaction. Knowledge of these factors could help implementers to match interventions as solutions to specific problems.

\section{INTRODUCTION}

\section{Rationale}

The mental image of medical house calls is one of archaic practices in small towns and otherwise rural communities, or something associated with concierge medicine. However, telehealth brings the doctor back into the patient's home. Healthcare has begun transitioning to more technological-delivered services, making it possible to receive healthcare services from the comfort of one's home, without driving to the clinic, or frustratingly trying to find a parking spot before one's appointment. This review examines telehealth and any association it might have with patient satisfaction.

This review uses the definition of telehealth from WHO:

The delivery of health care services, where distance is a critical factor, by all health care professionals using
Strengths and limitations of this study

- Inserting technology into a medical intervention should not be without deliberate design. This review serves as a voice of the patient to help guard against the implementation of technology merely for its convenience or shiny appeal.

- This study uses the Preferred Reporting Items for Systematic Reviews and Meta Analysis standard, which is an internationally recognised protocol for the conduct and reporting of systematic reviews that increases the validity of the results.

- A group >30 selected from Medical Subject Headings key terms indexed through established research databases increases the reliability of the review.

- Published studies do not often clearly set out reasons for inserting technology into an intervention, and therefore, it is not clear whether the patient satisfaction observed was congruent with the change of intervention.

- Telehealth, in general, is a relatively new topic in medicine (since the 1990s) so inferences that result from studies are difficult to compare to older, more traditional interventions.

information and communication technologies, for the exchange of valid information for diagnosis, treatment, and prevention of disease and injuries, research and evaluation, and for the continuing education of health care providers, in all the interests of advancing the health of individuals and their communities. ${ }^{1}$

Following WHO's example, we did not distinguish between telehealth and telemedicine; instead we used the term telehealth to address both telehealth and telemedicine. ${ }^{1}$ This broad definition of telehealth encompasses several modes of delivery, such as videoconferencing, mobile applications and secure messaging. WHO recognises several branches of telemedicine: teleradiology, teledermatology, telepathology and telepsychology. ${ }^{1}$ With the increased use of technology in healthcare, there has been a great emphasis on telehealth 
because it can extend the services of providers to remote locations and capitalise on the availability of subject matter experts and overcome the barrier of proximity. Telehealth extends access, and it has the potential of making healthcare services more convenient for patients, especially those in rural areas, those with small children (child care) and those with mobility restrictions. ${ }^{23}$

Patient satisfaction is a growing concern in all aspects of healthcare, and as the voice of the customer, it is a measure of quality that is published in the USA through its Healthcare Effectiveness Data and Information Set, and it can be tied to reimbursements from the Center for Medicare and Medicaid through results of Hospital Consumer Assessment of Healthcare Providers and Systems. As with traditional modalities of healthcare delivery, telehealth relies heavily on reports of patient satisfaction because the patients are the only source of information that can report how they were treated and if the treatment received met the patients' expectations of care. ${ }^{45}$ If the patients are not happy with their healthcare services being provided remotely, the service becomes redundant and expensive. With the increase in prevalence of telehealth, it is important to maintain the key quality indicator of patient satisfaction regardless of modality of delivery. The voice of the customer needs to be continuously heard so that telehealth developers can exercise agility in the development process while the healthcare organisation continues to develop more technology-based care that meets the needs of patients and providers. The technology base inherent to telehealth dramatically changes the mode of delivery, but a strong patient-to-provider relationship must be maintained independent of the modality. A definition of patient satisfaction, effectiveness and efficiency is provided at the end of the article.

\section{Objective}

We had multiple research questions. R1: Is there an association of telehealth with patient satisfaction? R2: Are there common facilitators of either efficiency or effectiveness mentioned in the literature that would provide a positive or negative association between telehealth and patient satisfaction?

\section{METHODS}

\section{Information sources, search and study selection}

The two sources of data were the Cumulative Index of Nursing and Allied Health Literature (CINAHL) via EBSCOhost and PubMed (MEDLINE). We used the Preferred Reporting Items for Systematic Reviews and Meta Analysis as our basis of organisation. ${ }^{6}$ We used a variety of key search terms, as listed in the Medical Subject Headings combined with Boolean operators. Search terms were adapted for use in the different databases. Details for each database are provided as onlinesupplementary file 1 .

Inclusion criteria were 2010-2017, English only, full text available and human research. We also filtered for all but academic publications (peer-reviewed in CINAHL) and in CINAHL we excluded MEDLINE to eliminate the duplicates already captured in PubMed. Instead of including reviews in the analysis, two reviews on a similar topic were earmarked for later comparison with our own results. Abstracts were reviewed for suitability based on our research concept that included both telehealth and some assessment of patient satisfaction.

\section{Data collection process}

A flow chart of our data collection process is located as online.supplementary material. Before reviewing abstracts for suitability to our objective, we agreed to look for articles that included telehealth and some measure of patient satisfaction. Articles were assessed according to the inclusion and exclusion criteria described above. Discussion sessions and consensus meetings were held to increase the inter-rater reliability of the group as they conducted the screening and analysis. During the consensus meetings, factors and themes were identified through observation and discussion; for example, as we discussed the articles, it became evident that patient satisfaction was often stated in terms of effectiveness and efficiency, so these became the themes.

Standard systematic review procedures were followed to control for selection bias and ensure our search was exhaustive.

Reviewers compiled their notes on patient satisfaction, effectiveness and efficiency in a literature matrix. Another consensus meeting was conducted to discuss findings and make inferences. During the consensus meeting, individual observations were discussed and combined into similar groupings throughout the sample to simplify our assessment of associations. This is a form of narrative analysis and sensemaking. ${ }^{7}$ Observations of effectiveness and efficiency were combined and sorted into an affinity matrix for final analysis.

\section{Data items and summary measures}

Our litmus test was to include articles that included a combination of telehealth and patient satisfaction, and a measure or assessment of effectiveness or efficiency. We eliminated those that fell short of those goals.

\section{Risk of bias in individual studies and risk of bias across studies}

Bias was discussed during consensus meetings. The consensus meetings served as a control on our own selection bias and selective reporting within studies.

\section{Summary measures and synthesis of results}

Our review examines articles that combine telehealth intervention with patient satisfaction and include some mention of effectiveness or efficiency. A physical count of these observations was made. After all observations were combined into an Excel file, and after all observations were condensed into themes of effectiveness or efficiency, all themes were displayed in an affinity matrix to identify the number of occurrences of each theme. These were sorted by frequency. 
CINAHL (by EBSCO)

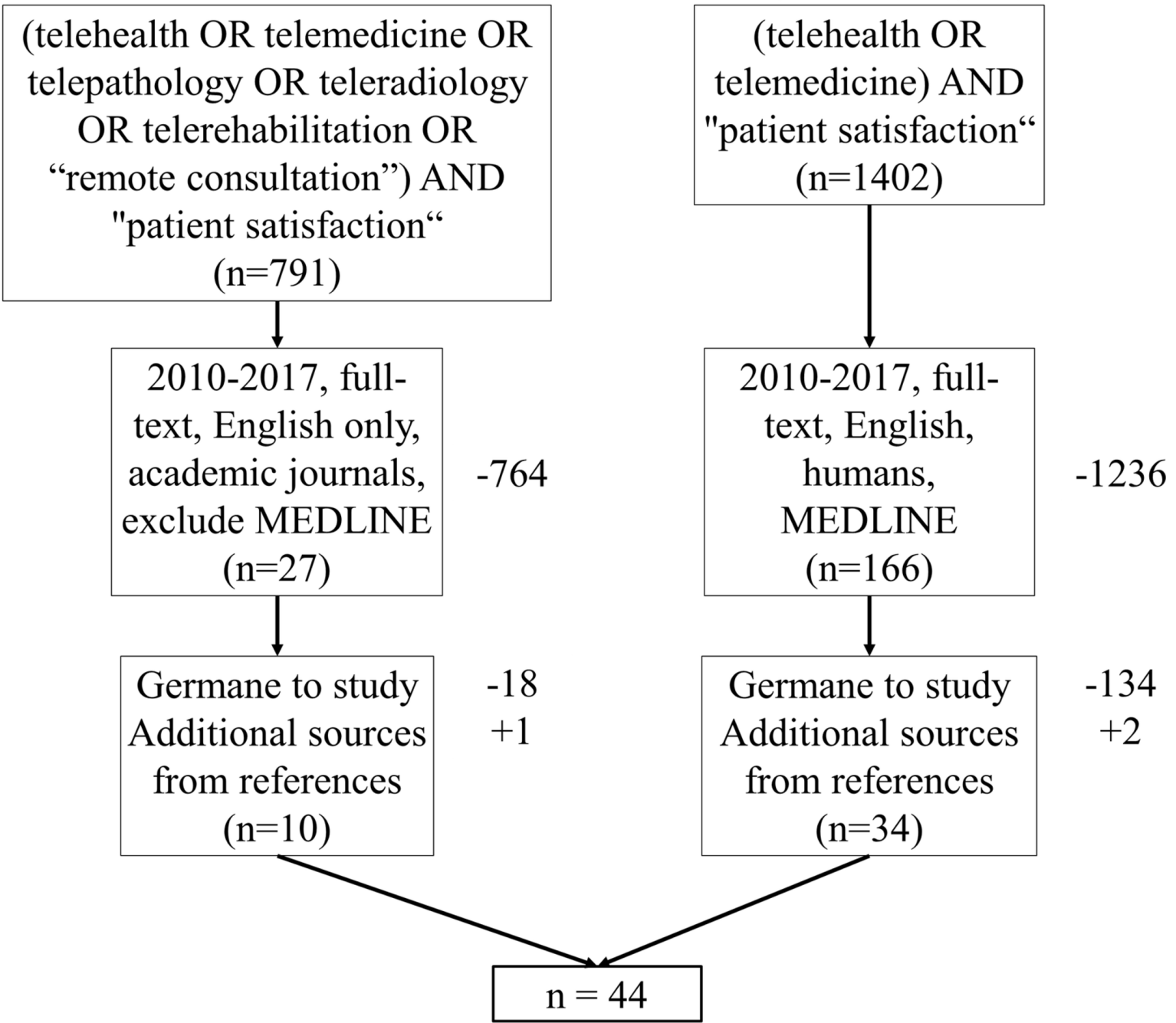

Figure 1 Literature search process with inclusion and exclusion criteria. CINAHL, Cumulative Index of Nursing and Allied Health Literature.

\section{RESULTS}

Study selection, study characteristics and results of individual studies

Our search process is illustrated in figure 1.

After the initial search yielded 2193 results, 193 underwent abstract and then full-text review resulting in 44 papers being included in the study.

Table 1 lists a summary of our analysis and observations from our team $(n=44)$. For every article/study in the sample, we made observations for satisfied, which was a screening criteria, and effective and efficient. Studies are listed in order of publication with the most recent at the top. The reference numbers correspond to those in the references section.

\section{Synthesis of results}

We analysed the way 44 articles reported patient satisfaction. $^{8-51}$ In tota, 24 911 13 15-18 21-25 27-29 323335384044 4547 studies reported patient views on effectiveness, $6^{101214304151}$ studies reported patient satisfaction and
$14^{19} 2026313436373942434648-50$ studies reported both. The third column lists comments and details that could point to selection bias. Potential risk of bias among papers included no randomisation, ${ }^{12}$ small sample size,${ }^{11} 13182123$ 2528333536414850 limited population, ${ }^{15} 2027293145-47$ gender bias, ${ }^{19} 20233847$ technology bias, ${ }^{18234450}$ selection bias, ${ }^{243238}$ geographically limited, ${ }^{8912141617343743}$ age bias,, ${ }^{29} 293844$ 51 education bias ${ }^{3038}$ and racial bias. ${ }^{44} 51$

\section{Additional analysis}

Table 2 outlines the frequency with which different factors were raised among the included paper. Through a narrative analysis we identified commonalities among the various studies (19 factors) and compiled them into an affinity matrix to show frequency of occurrence. The matrix is sorted by frequency of occurrence.

We acknowledge that frequency of occurrence does not equate to importance, but it has been used in other literature reviews as simply an issue of probability ${ }^{52-54}$ Five factors were mentioned in the literature 65/119 


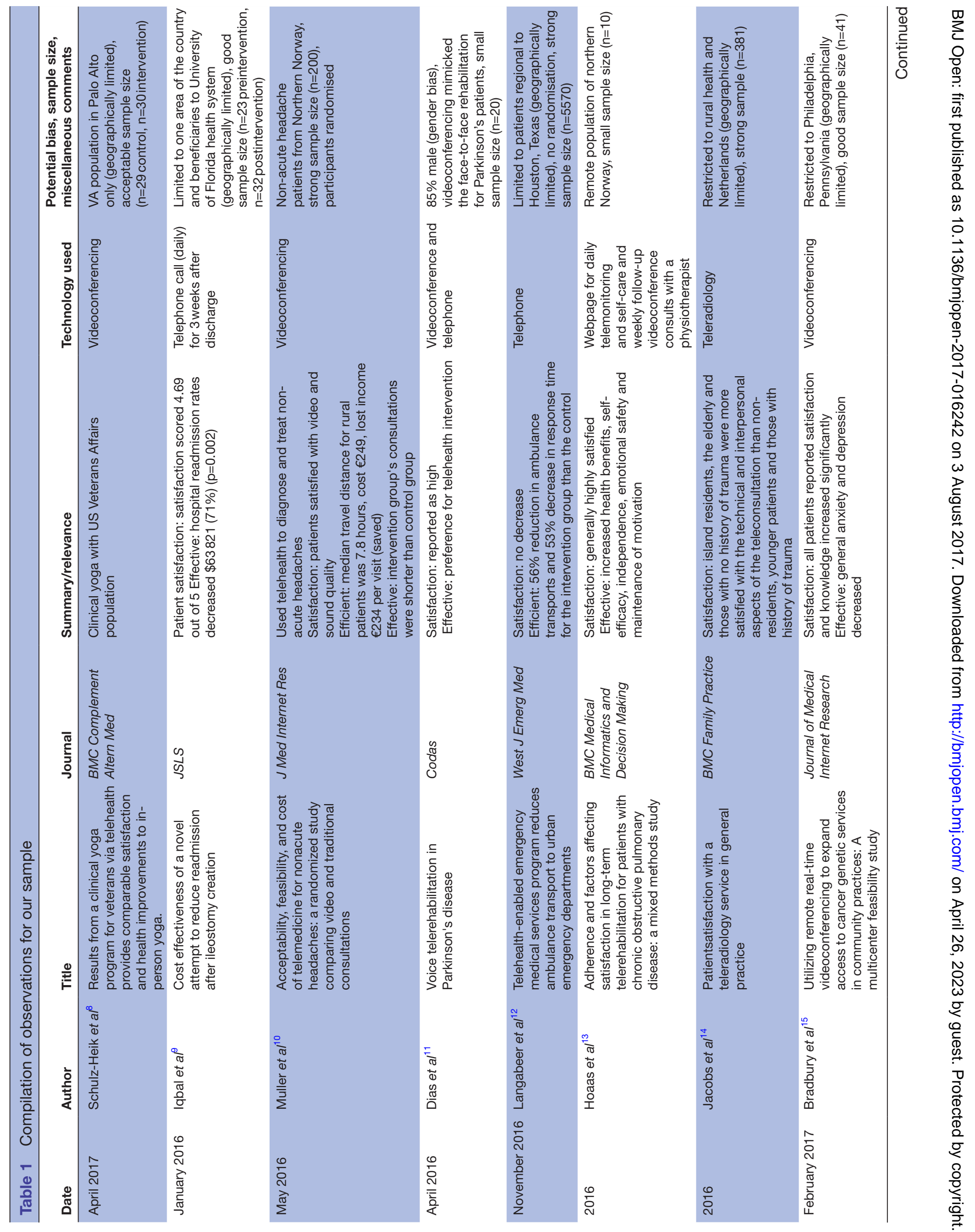




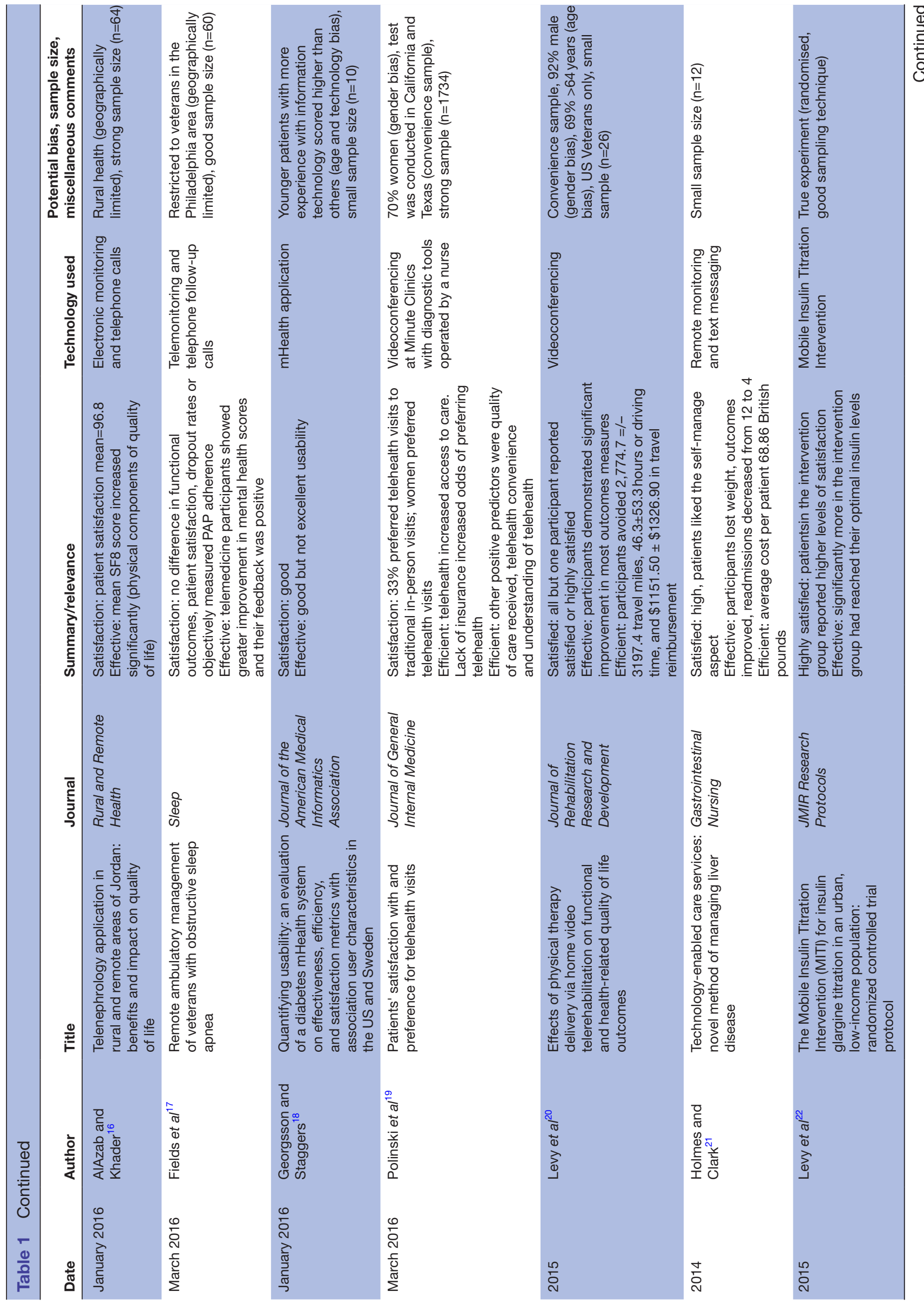




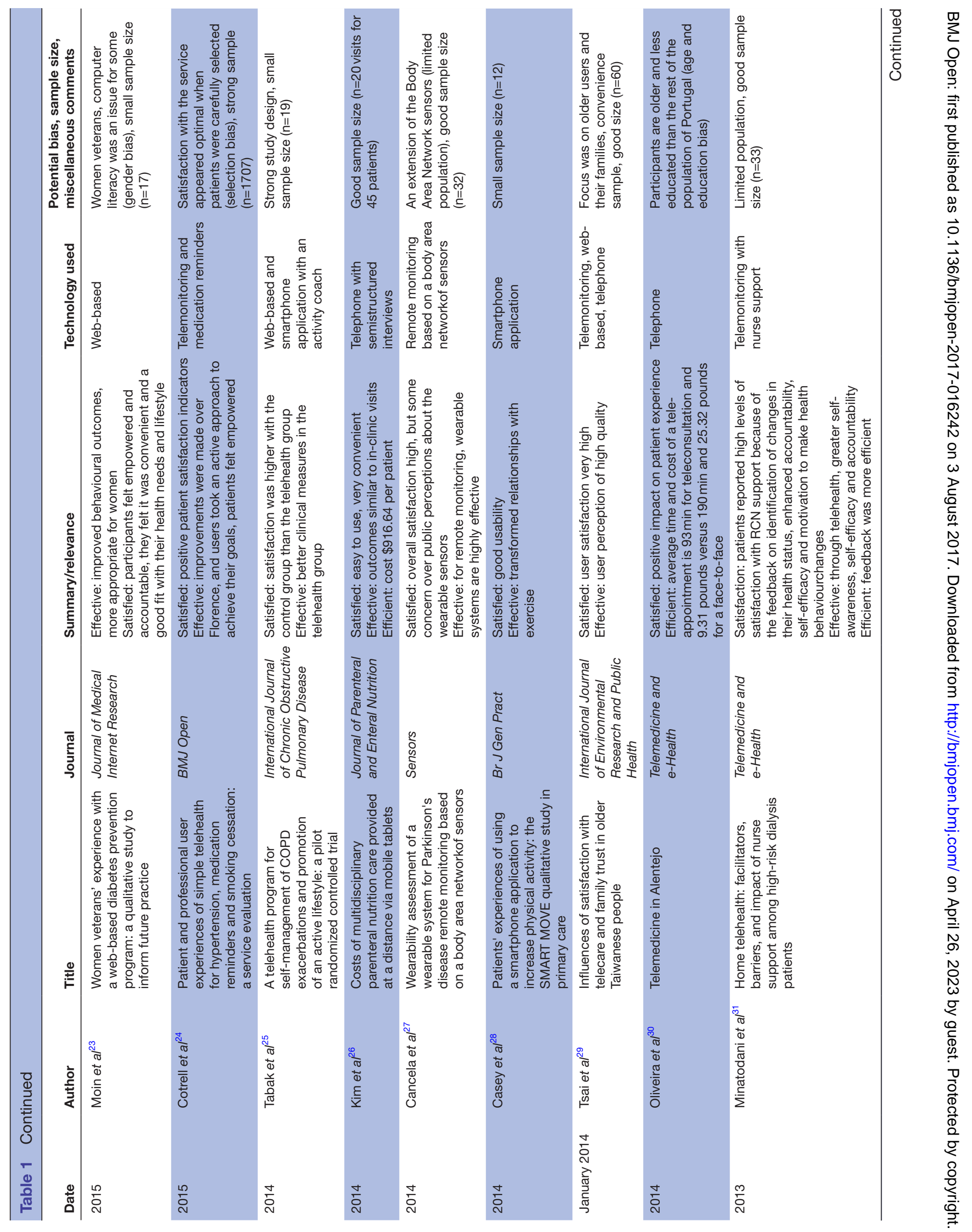




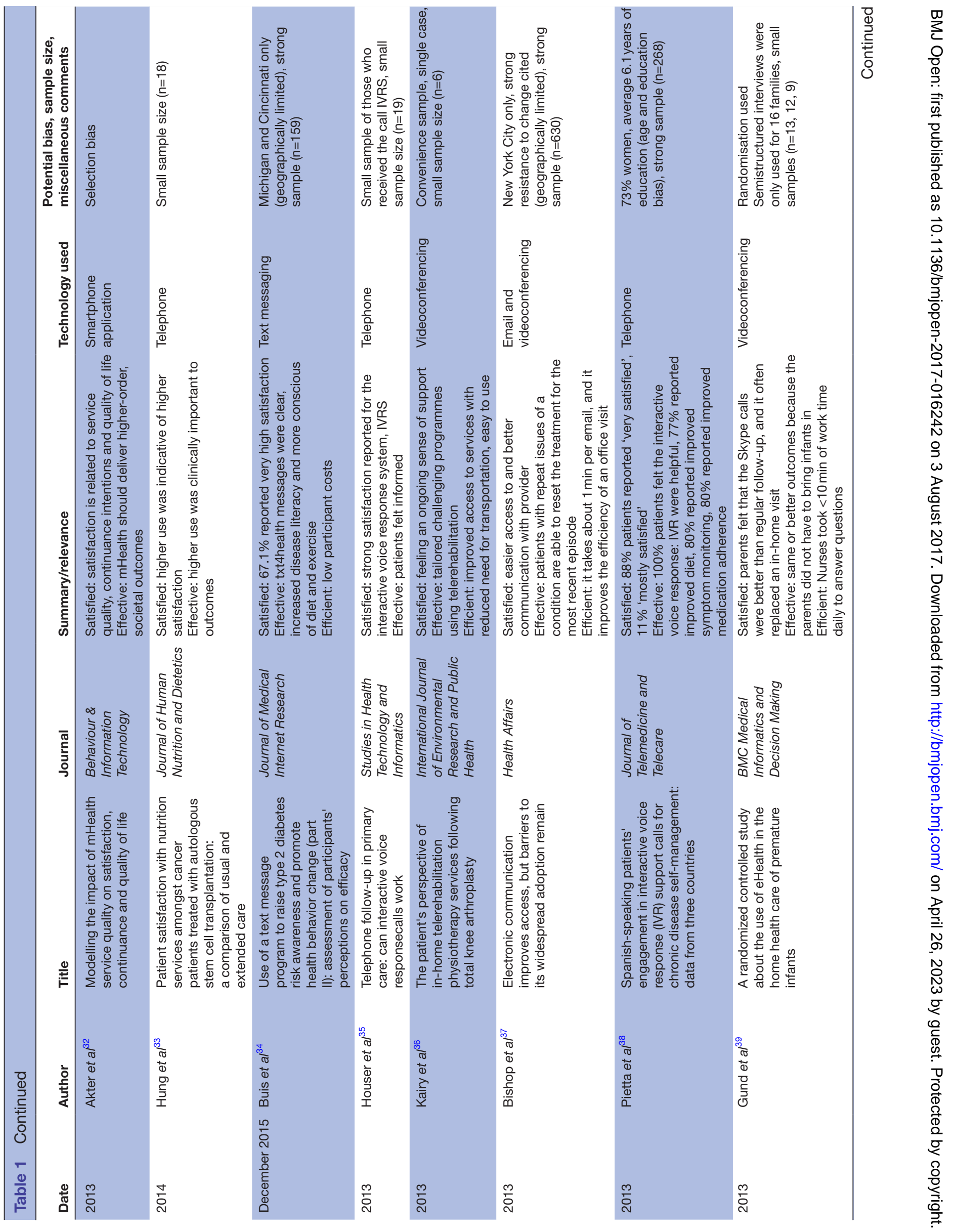




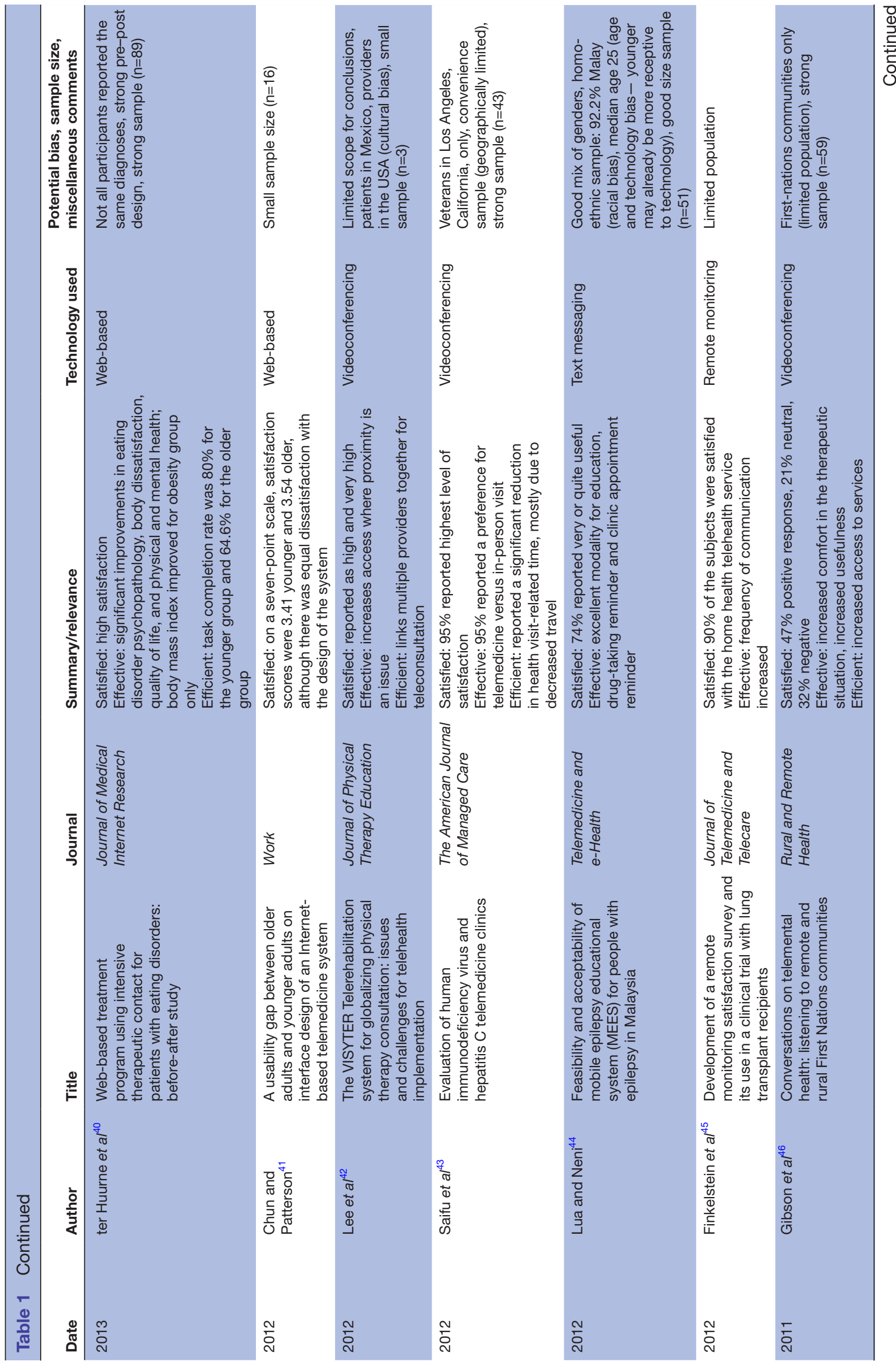




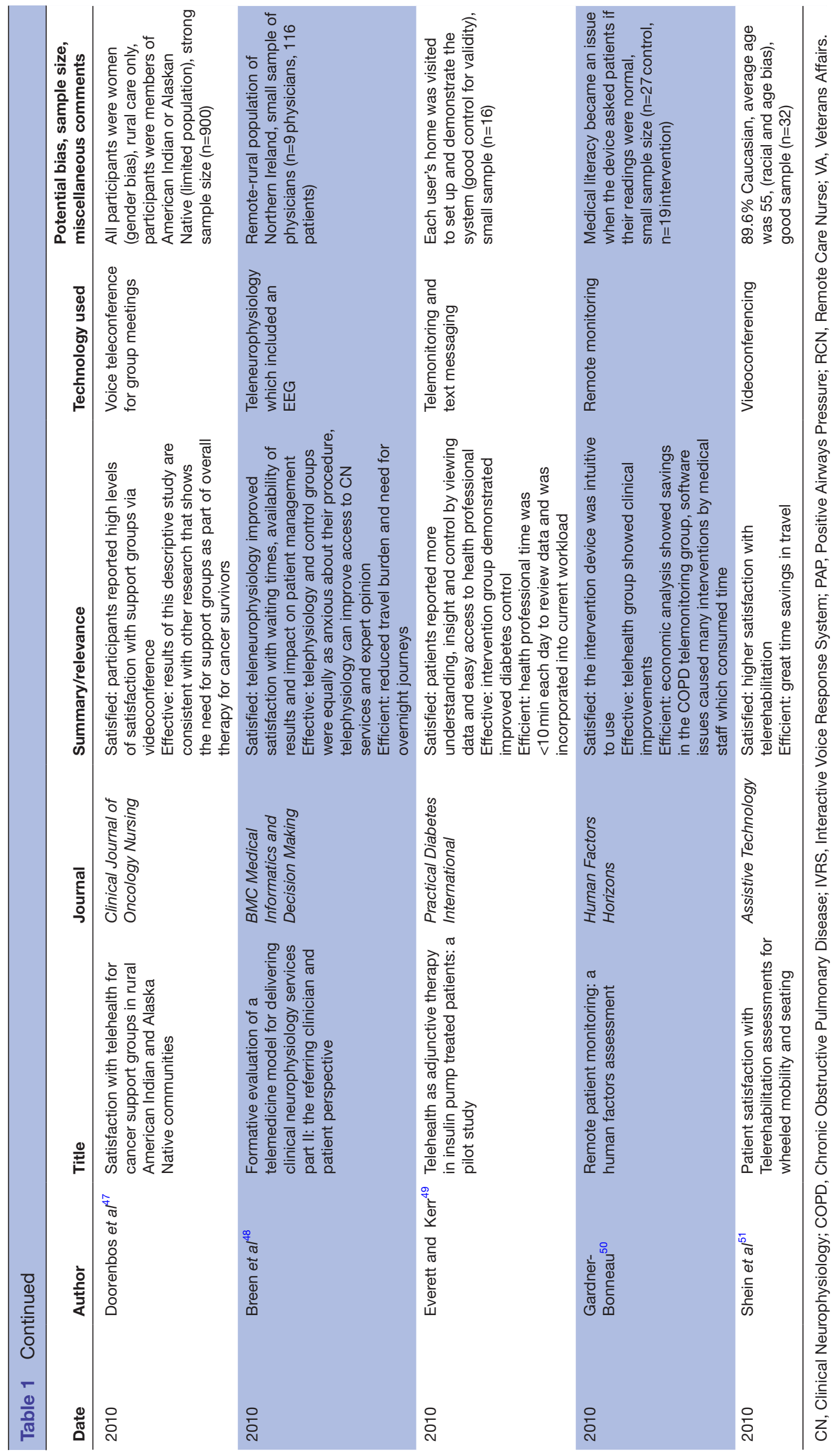


Open Access

Table 2 Affinity matrix

\begin{tabular}{llc}
\hline Factor & Article reference number & Frequency \\
\hline Improved outcomes & 8911 13 15-18 20-26 31-33 38-41 47 50 & 24 \\
\hline Preferred modality & 8911 14 15 19 22 26 34 43 44 46 & 12 \\
\hline Ease of use & $181923262836-38464950$ & 11 \\
\hline Low cost or cost savings & 101416202123263450 & 9 \\
\hline Improved communication & 242731363739424549 & 8 \\
\hline Travel time & 1012203036434851 & 7 \\
\hline Improved self-management & 13212328313248 & 5 \\
\hline Quality & 1619293240 & 4 \\
\hline Increased access & 19424648 & 4 \\
\hline Increased self-awareness & 31343538 & 4 \\
\hline Decreased wait times & 16434849 & 4 \\
\hline Fewer miles driven & 10142051 & 3 \\
\hline Decreased in-person visits & 123943 & 3 \\
\hline Improved self-efficacy & 132331 & 3 \\
Good modality for education & 153444 & 3 \\
\hline Low time to manage & 373949 & 3 \\
\hline Improved medication adherence & 133844 & 2 \\
\hline Decreased readmissions & 921 & 1 \\
\hline Fewer missed appointments & 44 & 119 \\
\hline
\end{tabular}

occurrences (55\%): improved outcomes, 891113 15-18 20-26 31-33 ${ }^{38-414750}$ preferred modality, ${ }^{8} 911141519222634434446$ ease of use, ${ }^{18}$ $1923262836-38464950$ low cost or cost savings, 101416202123263450 and improved communication. 242731363739424549

\section{DISCUSSION}

\section{Summary of evidence}

Telehealth has the potential to extend the boundaries of providers' practices by overcoming the barrier of proximity. Along with the introduction of a new modality of care comes change, and the literature mentioned various reactions to this change. One study identified heavy resistance to change, ${ }^{29}{ }^{37}$ while others mentioned an embrace of the change. ${ }^{29} 48$ Older patients, in general, do not embrace change, but recent studies have identified a generational acceptance of technology and mHealth in general. $^{55}$

Our findings from this systematic review and narrative analysis identify some issues that are salient in the literature. To help overcome provider resistance to change to telehealth, it should be noted that over the last 7 years $20 \%$ of the factors of effectiveness in the literature were improved outcomes. Providers and patients should embrace telehealth modalities because of its ease of use, ${ }^{18} 1923262836-38464950$ its tendency to improve outcomes $^{8} 91113$ 15-18 20-26 31-33 38-41 4750 and communication, ${ }^{242731363739424549}$ and its low cost. ${ }^{101416202123263450}$ It can decrease travel time $e^{1012203036434851}$ and increase communication with providers. Telehealth can provide a high-quality service, increase access to care, ${ }^{19} 424648$ increase self-awareness 31343538 and item powers patients to manage their chronic conditions. 13212328313248 Healthcare organisations should embrace telehealth because it decreases missed appointments, ${ }^{44}$ is a good modality for education, ${ }^{15} 3444$ decreases wait times, ${ }^{16} 434849$ decreases readmissions $^{9} 21$ and improves medication adherence. $^{133844}$ But most importantly, policymakers need to help legislation catch up with the technology by enabling additional means of reimbursement for telehealth because the modality improves outcomes, 8911 13 15-18 20-26 31-33 38-41 4750 which improves public health.

\section{Comparison}

The results of our review and narrative analysis are consistent with other reviews. Health outcomes have been identified as a factor of effectiveness in chronically ill patients in multiple studies. ${ }^{56}$ Improvements have been identified for both physical and behavioural conditions. The review by de Jong et al, did not identify a significant decrease in use. ${ }^{56}$ This review also focused on interventions that used asynchronous communication, like email and text messages, with an older population. Our study included both asynchronous and synchronous interventions with all ages.

We were able to locate a study from 2011 that also evaluated telehealth and patient satisfaction. ${ }^{57}$ The researchers used secondary data analysis as the basis 
for their study. Their study focused on patient satisfaction and home telehealth in US Veterans. Similar to the de Jong review, this study focused on an older population ranging from 55 to 87 , while our analysis included younger age groups. Its focus on US Veterans while ours included this group as only part of our population. Our approach can equate to a greater external validity to our analysis. The Young et al review found that its participants were extremely satisfied with the care coordination/home telehealth programme. The US Veterans in this review embraced the new modality. The researchers found a decrease in use associated with the telehealth modality.

\section{Limitations}

We identified several limitations in the conduct of our literature review and narrative analysis. Selection bias is possible within this study; however, our group consensus methods will have mitigated against this risk. Publication bias is another risk, particularly as we did not extend our search to the grey literature. Limiting our search to only two databases could easily have omitted valid articles for our review. We controlled for inter-rater reliability through the initial focus study of the topic followed by several consensus meetings held along the iterative process. By continuing to review our findings, we follow the example of other reviews and narrative analyses. ${ }^{52-55}$

The final limitation that we identified was the young age of the telehealth modality of care. It has existed since the early 1990s, but compared with traditional medicine, it is quite young. Because it is technologically based, we chose to only look at the last five years, which could also limit our findings, but the rapid advancement of a technologically based modality drives a more recent sample to make current observations and conclusions.

\section{CONCLUSIONS}

Overall, it was found that patient satisfaction can be associated with the modality of telehealth, but factors of effectiveness and efficiency are mixed. We found that patients' expectations were met when providers delivered healthcare via videoconference or any other telehealth method. Telehealth is a feasible option for providers who want to expand their practices to remote areas without having to relocate or expand their footprint of their practice. As telehealth continues to be developed, special care should be given to incorporate features that enable acceptance and reimbursement of this modality.

\section{Basic definitions}

Patient satisfaction: The U.S. Center for Medicare and Medicaid Services defines this term as the patient's perspective of care which can be objective and meaningful to create comparisons of hospitals and other healthcare organisations. $^{58}$

Effective: Successful or achieving the results that you want. ${ }^{59}$ Usually associated with outcomes.
Efficient: Performing or functi8oning in the best possible manner with the least waste of time and effort; having and using requisite knowledge, skill and industry. ${ }^{60}$

Acknowledgements The authors acknowledge Texas State University for using their library database for their research.

Contributors CK directed the initial research, served as lead author, mediated discussions about the merit of abstracts/articles, integrated the input from all team members and helped refine the figure and tables to provide continuity and flow. NK contributed the initial draft of the introduction and integrated her viewpoints into the methods, discussion and worked with JV on the in-text citations. BR contributed the initial draft of the abstract and integrated her viewpoints into the methods, discussion (benefits). LT created the initial draft of figure 1 (literature review process) and the initial draft of benefits and barriers charts. JV integrated her viewpoints into the methods, the initial draft of the discussion (barriers) section and worked with NK on the in-text citations. MB served as an expert in research in U.S. Veterans due to his research in this area, and he contributed meaningful contribution to the formation of analysis and conclusion.

Competing interests None declared

Provenance and peer review Not commissioned; externally peer reviewed. Data sharing statement All data are freely available.

Open Access This is an Open Access article distributed in accordance with the Creative Commons Attribution Non Commercial (CC BY-NC 4.0) license, which permits others to distribute, remix, adapt, build upon this work non-commercially, and license their derivative works on different terms, provided the original work is properly cited and the use is non-commercial. See: http://creativecommons.org/ licenses/by-nc/4.0/

(c) Article author(s) (or their employer(s) unless otherwise stated in the text of the article) 2017. All rights reserved. No commercial use is permitted unless otherwise expressly granted.

\section{REFERENCES}

1. World Health Organization. Telemedicine: opportunities and developments in Member States: report on the second global survey on eHealth: World Health Organization, 2010.

2. Finkelstein SM, Speedie SM, Potthoff S, et al. Home telehealth improves clinical outcomes at lower cost for home healthcare. Telemed J E Health 2006;12:128-36.

3. Rojas SV, Gagnon MP. A systematic review of the key indicators for assessing telehomecare cost-effectiveness. Telemed J E Health 2008;14:896-904.

4. Cleary PD. A hospitalization from hell: a patient's perspective on quality. Ann Intern Med 2003;138:33-9.

5. LaBarbera PA, Mazursky D. A Longitudinal Assessment of Consumer satisfaction/Dissatisfaction: the Dynamic Aspect of the Cognitive process. Journal of Marketing Research 1983;20:393-404.

6. Moher D, Liberati A, Tetzlaff J, et al.Preferred reporting items for systematic reviews and meta-analyses: the PRISMA statement. Ann Intern Med 2009;151:264-9.

7. Kohler C. Narrative analysis . 30, 1993.

8. Schulz-Heik RJ, Meyer H, Mahoney L, et al. Results from a clinical yoga program for veterans: yoga via telehealth provides comparable satisfaction and health improvements to in-person yoga. BMC Complement Altern Med 2017;17:198.

9. Iqbal A, Raza A, Huang E, et al. Cost effectiveness of a novel attempt to reduce readmission after lleostomy Creation. JSLS 2017;21:e2016.00082.

10. Müller KI, Alstadhaug KB, Bekkelund SI, et al. Acceptability, feasibility, and cost of telemedicine for nonacute headaches:a randomized study comparing video and Traditional consultations.. Journal of medical Internet research 2016;18:e140.

11. Dias AE, Limongi JCP, Hsing WT, et al. Telerehabilitation in Parkinson's disease: Influence of cognitive status. Dement Neuropsychol 2016;10:327-32.

12. Langabeer JR, Gonzalez M, Alqusairi D, et al. Telehealth-Enabled Emergency Medical Services Program reduces Ambulance transport to Urban Emergency Departments. West J Emerg Med 2016;17:713-20.

13. Hoaas $\mathrm{H}$, Andreassen HK, Lien LA, et al. Adherence and factors affecting satisfaction in long-term telerehabilitation for patients with 
chronic obstructive pulmonary disease: a mixed methods study. BMC Med Inform Decis Mak 2016;16:26.

14. Jacobs JJ, Ekkelboom R, Jacobs JP, et al. Patient satisfaction with a teleradiology service in general practice. BMC Fam Pract 2016;17:17:17.

15. Bradbury A, Patrick-Miller L, Harris D, et al. Utilizing remote RealTime videoconferencing to expand access to Cancer genetic Services in Community Practices: a Multicenter Feasibility Study. J Med Internet Res 2016;18:e23.

16. AlAzab R, Khader Y. Telenephrology application in rural and remote Areas of Jordan: benefits and impact on quality of life. Rural Remote Health 2016;16.

17. Fields BG, Behari PP, McCloskey S, et al. Remote Ambulatory Management of Veterans with Obstructive Sleep Apnea. Sleep 2016;39:501-.

18. Georgsson M, Staggers N. Quantifying usability: an evaluation of a diabetes mHealth system on effectiveness, efficiency, and satisfaction metrics with associated user characteristics. J Am Med Inform Assoc 2016;23:5-11.

19. Polinski JM, Barker T, Gagliano N, et al. PatientsSatisfaction with and preference for Telehealth Visits. J Gen Intern Med 2016;31:269-75.

20. Levy $\mathrm{CE}$, Silverman $\mathrm{E}$, Jia $\mathrm{H}$, et al. Effects of physical therapy delivery via home video telerehabilitation on functional and health-related quality of life outcomes. J Rehabil Res Dev 2015;52:361-70.

21. Holmes M, Clark S. Technology-enabled care services: novel method of managing liver disease. Gastrointestinal Nursing 2014;12:S22-S27.

22. Levy N, Moynihan V, Nilo A, et al. The Mobile insulin titration intervention (MITI) for insulin glargine titration in an Urban, LowIncome Population: randomized Controlled Trial Protocol. JMIR Res Protoc 2015:4:e31.

23. Moin T, Ertl K, Schneider J, et al. Women veterans' experience with a web-based diabetes prevention program: a qualitative study to inform future practice. J Med Internet Res 2015:17:e127.

24. Cottrell E, Cox T, O'Connell P, et al. Patient and professional user experiences of simple telehealth for hypertension, medication reminders and smoking cessation: a service evaluation. BMJ Open 2015;5:e007270.

25. Tabak M, Brusse-Keizer M, van der Valk $P$, et al. A telehealth program for self-management of COPD exacerbations and promotion of an active lifestyle: a pilot randomized controlled trial. Int J Chron Obstruct Pulmon Dis 2014;9:935

26. Kim H, Spaulding R, Werkowitch M, et al. Costs of multidisciplinary parenteral nutrition care provided at a distance via mobile tablets. JPEN J Parenter Enteral Nutr 2014;38:50S-7.

27. Cancela J, Pastorino M, Tzallas AT, et al. Wearability assessment of a wearable system for Parkinson's disease remote monitoring based on a body area network of sensors. Sensors 2014;14:17235-55.

28. Casey M, Hayes PS, Glynn F, et al. Patients' experiences of using a smartphone application to increase physical activity: the SMART MOVE qualitative study in primary care. Br J Gen Pract 2014;64:e500-e508.

29. Tsai CH, Kuo YM, Uei SL, et al. Influences of satisfaction with telecare and family trust in older taiwanese people. Int J Environ Res Public Health 2014:11:1359-68.

30. Oliveira TC, Bayer S, Gonçalves L, et al. Telemedicine in Alentejo. Telemed J E Health 2014;20:90-3.

31. Minatodani DE, Chao PJ, Berman SJ, et al. Home telehealth: facilitators, barriers, and impact of nurse support among high-risk dialysis patients. Telemed J E Health 2013;19:573-8.

32. Akter S, D'Ambra J, Ray P, et al. Modelling the impact of $m$ Health service quality on satisfaction, continuance and quality of life. Behav Inf Technol 2013;32:1225-41.

33. Hung YC, Bauer J, Horsley P, et al. Patient satisfaction with nutrition services amongst Cancer patients treated with autologous stem cell transplantation: a comparison of usual and extended care. J Hum Nutr Diet 2014;27 Suppl 2:333-8.

34. Buis LR, Hirzel L, Turske SA, et al. Use of a text message program to raise type 2 diabetes risk awareness and promote health behavior change (part I): assessment of participant reach and adoption. J Med Internet Res 2013;15:e282.

35. Houser SH, Ray MN, Maisiak R, et al. Telephone follow-up in primary care: can interactive voice response calls work? Stud Health Technol Inform 2013;192:112.
36. Kairy D, Tousignant M, Leclerc N, et al. The patient's perspective of in-home telerehabilitation physiotherapy services following total knee arthroplasty. Int J Environ Res Public Health 2013;10:3998-4011.

37. Bishop TF, Press MJ, Mendelsohn JL, et al. Electronic communication improves access, but barriers to its widespread adoption remain. Health Aff 2013;32:1361-7.

38. Piette JD, Marinec N, Gallegos-Cabriales EC, et al. Spanish-speaking patients' engagement in interactive voice response (IVR) support calls for chronic disease self-management: data from three countries. J Telemed Telecare 2013;19:89-94.

39. Gund A, Sjöqvist BA, Wigert $\mathrm{H}$, et al. A randomized controlled study about the use of eHealth in the home health care of premature infants. BMC Med Inform Decis Mak 2013;13:1.

40. ter Huurne ED, Postel MG, de Haan HA, et al. Web-based treatment program using intensive therapeutic contact for patients with eating disorders: before-after study. J Med Internet Res 2013;15:e12.

41. Chun YJ, Patterson PE. A usability gap between older adults and younger adults on interface design of an Internet-based telemedicine system. Work 2012;41 Suppl 1:349-52.

42. Lee AC, Pulantara W, Barbara Sargent PT, et al. The VISYTER telerehabilitation system for globalizing physical therapy consultation: issues and challenges for telehealth implementation. Journal of Physical Therapy Education 2012;26:90.

43. Saifu HN, Asch SM, Goetz MB, et al. Evaluation of human immunodeficiency virus and hepatitis $\mathrm{C}$ telemedicine clinics. Am J Manag Care 2012:18:207-12.

44. Lua PL, Neni WS. Feasibility and acceptability of mobile epilepsy educational system (MEES) for people with epilepsy in Malaysia. Telemed J E Health 2012;18:777-84.

45. Finkelstein SM, MacMahon K, Lindgren BR, et al. Development of a remote monitoring satisfaction survey and its use in a clinical trial with lung transplant recipients. J Telemed Telecare 2012;18:42-6.

46. Gibson KL, Coulson H, Miles R, et al. Conversations on telemental health: listening to remote and rural first nations communities. Rural Remote Health 2011;11:1656-74.

47. Doorenbos AZ, Eaton LH, Haozous E, et al. Satisfaction with telehealth for Cancer support groups in rural american indian and Alaska native communities. Clin J Oncol Nurs 2010;14:765-70.

48. Breen P, Murphy K, Browne G, et al. Formative evaluation of a telemedicine model for delivering clinical neurophysiology services part I: utility, technical performance and service provider perspective. BMC Med Inform Decis Mak 2010:10:1-8.

49. Everett J, Kerr D. Telehealth as adjunctive therapy in insulin pump treated patients: a pilot study. Practical Diabetes International 2010;27:9-10.

50. Gardner-Bonneau D. Remote patient monitoring: a human factors Assessment. Biomed Instrum Technol 2010;44:71-7.

51. Schein RM, Schmeler MR, Saptono A, et al. Patient satisfaction with telerehabilitation assessments for wheeled mobility and seating. Assist Technol 2010;22:215-22.

52. Kruse CS, Kothman K, Anerobi K, et al. Adoption factors of the Electronic Health Record: a Systematic Review. JMIR Med Inform 2016;4:e19.

53. Kruse CS, Mileski M, Alaytsev V, et al. Adoption factors associated with electronic health record among long-term care facilities: a systematic review. BMJ Open 2015;5:e006615.

54. Luna R, Rhine E, Myhra M, et al. Cyber threats to health information systems: a systematic review. Technol Health Care 2016;24:1-9.

55. Kruse CS, Mileski M, Moreno J, et al. Mobile health solutions for the aging population:a systematic narrative analysis. J Telemed Telecare 2017;23:1-13.

56. de Jong CC, Ros WJ, Schrijvers G, et al. The effects on health behavior and health outcomes of Internet-based asynchronous communication between health providers and patients with a chronic condition: a systematic review. J Med Internet Res 2014;16:e19.

57. Young LB, Foster L, Silander A, et al. Home telehealth: patient satisfaction, program functions, and challenges for the care coordinator. J Gerontol Nurs 2011;37:38-46

58. U.S. Center for Medicare and Medicaid Services. HCAHPS: patient's perspectives of care surve. https://www.cms.gov/medicare/qualityinitiatives-patient-assessment-instruments.html (accessed $30 \mathrm{Apr}$ 2017).

59. Cambridge Dictionary Effective. dictionary.cambridge.org/dictionary/ English/effective (accessed 30 Apr 2017).

60. Dictionary.com Efficient. www.dictionary.com/browse/efficient (accessed 30 Apr2017). 